\title{
KAJIAN SIFAT FISIKA TANAH PADA PERTUMBUHAN TANAMAN MANGGIS (Garcinia mangostana L.) DI KABUPATEN LIMA PULUH KOTA
}

\author{
Yulnafatmawita, Adrinal, dan Sudewi Isminingsih \\ J urusan Tanah F akultas Pertanian U niversitas Andalas Padang
}

\begin{abstract}
This research was aimed to evaluate physical properties of soils grown by mangosteen crops in Lima Puluh Kota Regency, especially in Kecamatan Payakumbuh and Kecamatan Guguk, in West Sumatra. Soils were sampled by using sample rings for undisturbed and by using soil driller for disturbed samples on 0-20, 20-40, and 40-60 cm soil depth. Soil samples were analyzed in Soil Laboratory Agriculture Faculty, Andalas University, Padang. The results showed that soil texture in two locations was similar, that was silty loam for the $0-40 \mathrm{~cm}$ depth, and clay for the 40-60 depth. However, generally soil organic matter content in Guguk was lower than that in Payakumbuh, that was medium to low, BV from low to high, total porosity from high to medium, and permeability from high to slightly slow.
\end{abstract}

Key Words: Soil physical properties, mangostana

\section{PENDAHULUAN}

Informasi sumber daya lahan merupakan suatu data yang sangat penting dalam perencanaan pembangunan wilayah terutama di bidang pertanian. Sumberdaya lahan merupakan salah satu faktor fisik utama untuk dipertimbangkan dalam perencanaan, penyusunan dan pelaksanaan tata ruang terutama di daratan. Pengembangan suatu wilayah tidak akan maksimal bahkan bisa berakibat buruk kepada kehidupan sosial dan ekonomi masyarakat, jika suatu lahan dibuka dan diusahakan tidak sesuai dengan potensi lahan itu sendiri.

Ada beberapa data yang dapat digunakan sebagai data dasar diantaranya data agroklimat (Yuniarti et al, 2008), data kesuburan tanah, baik kesuburan fisika, kimia, maupun biologi tanah di samping data sosial masyarakat. Diantara tiga bagian kesuburan tanah, kesuburan fisik suatu tanah atau lahan biasanya dipertimbangkan diawal perencanaan pengunaan lahan, agar produkstifits lahan bisa dengan mudah dipelihara dan ditingkatkan.

Kondisi fisik suatu tanah akan menentukan pertumbuhan tanaman diatasnya. Hal ini disebabkan karena sifat fisika tanah bukan saja mempengaruhi ketersediaan air dan udara yang cukup bagi pertumbuhan tanaman, tetapi kondisi fisik suatu tanah juga akan mempengaruhi kelarutan hara dan pengambilannya oleh tanaman, serta aktifitas biologi tanah. Setiap tanaman akan membutuhkan lingkungan fisik yang berbeda bagi pertumbuhannya yang optimal. Demikian juga halnya dengan pertumbuhan tanaman manggis.

Manggis merupakan tanaman tahunan atau pohon yang berkeping dua dan berakar tunggang. Tanaman ini tumbuh dan berkembang baik di daerah dengan ketinggian 4 meter sampai 800 meter diatas permukaan laut dan temperatur $22-32{ }^{\circ} \mathrm{C}$. Manggis ditemui tumbuh di beberapa daerah di Sumatra Barat, diantaranya yang terkenal di Sicincin Kabupaten Padang Pariaman dan Kabupaten Lima Puluh Kota. Kabupaten Lima Puluh Kota di Propinsi Sumatera Barat merupakan sentra komoditas hortikultura yang potensial, terutama buah-buahan diantaranya manggis. Komoditas manggis mulai berkembang di Kabupaten Lima Puluh Kota sejak tahun 1970 di Kecamatan Guguk dan Payakumbuh. Pada tahun \pm 1974 komoditas manggis ini telah menyebar keseluruh dataran disekitarnya.

Dewasa ini, buah manggis termasuk produk hortikultura atau sebangsa buahbuahan yang menjadi buah primadona Sumbar. Buah manggis berpotensi tingi untuk penyumbang devisa bagi SUMBAR. 
Manggis selain dipasarkan di daerah Sumbar sendiri, tetapi juga ke propinsi lain, bahkan sampai ke negara tetangga. Oleh sebab itu, pengembangan tanaman manggis di Sumbar merupakan pelang yang baik bagi pendapatan penduduk Minang.

Walaupun bukan daerah penghasil buah manggis terbanyak, Lima Puluh Kota dikenal sebagai daerah penghasil mutu terbaik. Apakah kualitas manggis disini ada hubungannya dengan faktor lingkungan pertumbuhan diantaranya sifat fisik tanah yang ditumbuhi manggis, menarik untuk diteliti. Dengan mengetahui kondisi fisik tanah yang ditumbuhi mangis, maka minimal dalam pengembangannya juga diusahakan pada kondisi fisik lahannya menyerupai kondisi fisik lahan yang ada di Kabupaten Lima Puluh Kota, khususnya di kecamatan Guguk dan Payakumbuh.

Berdasarkan hal diatas, maka telah dilakukan penelitian analisis sifat fisika tanah pada pertanaman manggis di Kabupaten Lima Puluh Kota. Tujuan penelitian ini adalah untuk menilai sifat fisika tanah yang ditumbuhi tanaman manggis di Kabupaten 50 Kota, khususnya di kecamatan Guguk dan Payakumbuh.

\section{BAHAN DAN METODA}

Penelitian ini terdiri dari tiga tahap yaitu: 1) studi kepustakaan, 2) survai tanah untuk pengambilan contoh tanah di lapangan, dan 3) analisis beberapa sifat fisika tanah di laboratorium Tanah Fakultas Pertanian Universitas Andalas Padang.

Studi kepustakaan mencakup pemilihan lokasi pengambilan contoh tanah berdasarkan informasi yang di dapat dari peta topografi, peta tanah dan peta penggunaan lahan daerah yang bersangkutan. Berdasarkan peta diatas, posisi geografi titik pengambilan sampel tanahnya ditentukan. Titik yang sudah diettapkan tersebut bisa dicari di lapangan dengan menggunakan GPS (Geographical Positioning Satellite).

Survai tanah dilakukan untuk mengambil contoh tanah sebagai bahan utama penelitian. Contoh tanah utuh untuk penetapan sifat fisika tanah diambil dengan ring sampel, dan sampel tanah terganggu diambil dengan bor Belgia. Saat survai tanah, dilakukan identifikasi warna tanah pada setiap kedalaman dengan Munsell Soil Color Chart.

Sampel tanah dibawa ke laboratorium tanah Fakultas Pertanian Unand untuk dianalisis. Sampel tanah terlebih dahulu dikering-anginkan, lalu sebahagian dihaluskan dan diayak dengan ukuran mesh yang sesuai dengan kebutuhan tanah untuk analisis. Setelah itu kadar air tanah diukur untuk KKA nantinya, selebihnya sampel tanah dimasukkan dalam kontainer (kotak) agar kadar airnya tidak brubah dan juga tidak terkontaminasi dengan sampel lain.

Pengamatan sifat dan ciri tanah meliputi: 1) Analisis C-organik tanah menggunakan metode Walkey and Black (Walkey, 1947 cit Tan, 1996), 2) analisis tekstur tanah dengan metoda Pipet dan Ayakan (Gee and Bowder, 1986), BV dan TRP dengan metoda gravimetri dengan contoh tanah dalam ring, 3) analisis permeabilitas dengan metoda Constant Head berdasarkan hukum Darcy. Data yang diperoleh dinilai berdasarkan kriteria sifat fisika tanah bagi pertumbuhan tanaman.

\section{HASIL DAN PEMBAHASAN}

\section{Kondisi Alam Kabupaten Lima Puluh Kota}

Daerah Kabupaten Lima Puluh Kota secara geografis berada pada $00^{\circ} 04^{\prime}-00^{0}$ $10^{\prime}$ LS dan $100^{\circ} 27^{\prime}-100^{\circ} 39^{\prime}$ BT dengan luas daerah pertanian sekitar $19.793 \mathrm{Ha}$, dan luas pertanaman manggis \pm 213 Ha terletak pada daerah dengan topografi datar sampai bergelombang. Secara agroklimat tanaman manggis di Kabupaten Lima Puluh Kota tumbuh pada curah hujan 100 sampai 2500 $\mathrm{mm} /$ tahun dengan kelembaban $70 \%$ dan temperatur rata-rata $25^{\circ} \mathrm{C}$ sampai $28^{\circ} \mathrm{C}$. Berdasarkan perhitungan dan analisis yang dilakukan terhadap data presipitasi (curah hujan) yang dikumpulkan oleh Berlage (1949), maka diperoleh presipitasi rata-rata tahunan $2238.773 \mathrm{~mm} /$ tahun, dengan jumlah hari hujan rata-rata 15 hari. Data presipitasi dapat dilihat pada Tabel 1 .

Pada Tabel 1. terlihat presipitasi 
Tabel 1. Rata-rata presipitasi bulanan dan tahunan di Kabupaten Lima Puluh Kota 10 tahun terakhir.

\begin{tabular}{lccr}
\hline \multicolumn{1}{c}{ Bulan } & $\begin{array}{c}\text { Rata-rata Presipitasi } \\
(\mathrm{mm})\end{array}$ & $\begin{array}{c}\text { Evapotranspirasi } \\
(\mathrm{mm})\end{array}$ & $\begin{array}{c}\text { Surplus air } \\
(\mathrm{mm})\end{array}$ \\
\hline Januari & 266.6818 & 108.2273 & 158.4545 \\
Februari & 204.2727 & 114.0000 & 90.2727 \\
Maret & 210.1818 & 137.3636 & 72.8182 \\
April & 267.8182 & 112.0909 & 155.7273 \\
Mei & 173.3636 & 134.5455 & 38.8181 \\
Juni & 90.9545 & 126.4545 & -35.5000 \\
Juli & 161.0000 & 119.2727 & 41.7273 \\
Agustus & 106.9545 & 115.8182 & -8.8637 \\
September & 140.0909 & 114.9091 & 25.1818 \\
Oktober & 190.0909 & 123.5455 & 66.5454 \\
November & 232.5455 & 116.0000 & 116.5455 \\
Desember & 194.8182 & 106.3182 & 88.5000 \\
\hline Total & 2238.7730 & 1428.5460 & 810.2272 \\
\hline
\end{tabular}

Sumber : Stasiun K limatologi Tanjung Pati, Harau (2005)

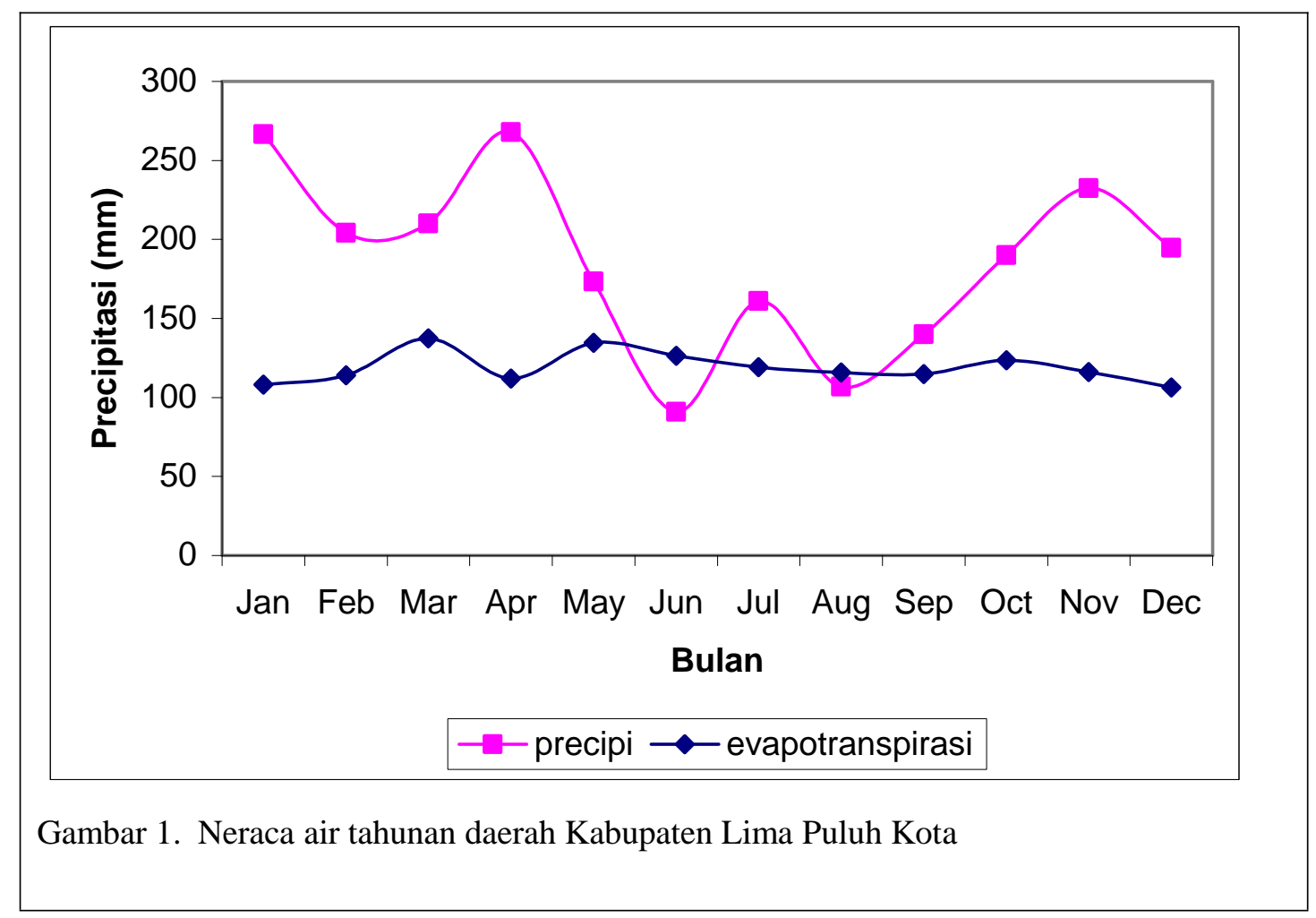


tertinggi terdapat pada bulan April. Selanjutnya dalam grafik neraca air pada Gambar 1. terlihat pada bulan-bulan tersebut presipitasi lebih tinggi daripada evapotranspirasi sehingga dapat digolongkan kedalam regim kelembaban Perudic (presipitasi setiap bulan selalu melebihi evapotranspirasi), dan kondisi ini menyebabkan terjadinya kelebihan air (surplus air). Hal ini jelas terlihat dalam neraca air daerah Kabupaten Lima Puluh Kota.

Berdasarkan klasifikasi iklim menurut Schmidt dan Ferguson (1951), tipe hujan di daerah ini termasuk pada daerah tipe iklim A (amat basah) dengan nilai quotien (Q) antara 0 dan 14,33\%. Sedangkan menurut klasifikasi Koppen termasuk tipe iklim Af, yaitu tipe iklim tropis atau selalu basah tanpa bulan kering. Suhu udara normal bulan terdingin lebih dari $18^{\circ} \mathrm{C}$, dan suhu bulan terpanas diatas $22^{\circ} \mathrm{C}$. Kondisi iklim tersebut dapat menunjang keberhasilan pertanian, khususnya tanaman manggis.

Sifat Fisika Tanah

\section{Tekstur Tanah}

Berdasarkan hasil analisis laboratorium, tekstur tanah pada lapisan 40 $\mathrm{cm}$ permukaan tanah termasuk agak kasar dan halus pada lapsan 40-60 cm pada ke dua wilayah yang diteliti, Kecamatan Guguk dan Kecamatan Payakumbuh. Seperti terlihat pada Tabel 2, tekstur tanah lapisan 0-40 cm didominasi oleh fraksi debu dan pasir, sedangkan lapisan 40-60 cm seimbang antara fraksi halus (liat) dan raksi kasar (pasir). Tekstur tanah yang kasar di kedua daerah penelitian ini kemungkinan besar berkaitan dengan ordo tanahnya yang bau berkembang, yaitu Inceptisols (Peta pada Lapiran 1 dan 2). Menurut Brady (1984) Inceptisols adalah tanah yang baru berkembang, lebih muda dari ordo tanah lainnya kecuali Entisols, profilnya belum memperlihatkan pelapukan yang intensif seperti penumpukan liat dan oksida besi dan aluminium. Inceptisols bisa terbentuk dari sediment atau lansekap yang muda atau lansekap tua yang proses pembentukan tanahnya terhambat (Foss et al, 1983). Berdasarkan proses kejadiannya yang masih baru dan juga proilnya yang belum melapuk intensif, maka teksturnya sebagian besar juga belum melapuk, atau termasuk kasar.

Tekstur tanah yang agak kasar, seperti lempung yaitu yang mempunyai fraksi pasir, dbu, dan liat yang hampr seimbang, akan bersifat lebih poros dari tanah dengan kandungan halus yang tinggi. Hal ini berarti bahwa tanah yang demikian akan mudah ditembus akar tanaman, jumlah air dan udara yang ditahan dalam tanah akan seimbang bagi pertumbuhan tanaman.

Tabel 2. Tekstur Tanah pada Pertanaman Manggis di Kecamatan Guguk dan Payakumbuh Kabupaten Lima Puluh Kota

\begin{tabular}{cccccc}
\hline \multirow{2}{*}{ Lokasi } & $\begin{array}{c}\text { Kedalaman } \\
(\mathrm{cm})\end{array}$ & Pasir & Debu & Liat & \multirow{2}{*}{ Kelas Tekstur } \\
\cline { 3 - 5 } & $0-20$ & 23.04 & 62.48 & 14.48 & Lempung berdebu \\
\hline \multirow{2}{*}{$\begin{array}{c}\text { Koto Baru Kec. } \\
\text { Payakumbuh }\end{array}$} & $20-40$ & 23.58 & 69.68 & 6.74 & Lempung berdebu \\
& $40-60$ & 38.01 & 23.89 & 38.11 & Liat \\
Kec. Guguk & $0-20$ & 24.80 & 39.99 & 35.25 & Lempung berdebu \\
& $20-40$ & 21.18 & 58.83 & 20.01 & Lempung berdebu \\
& $40-60$ & 35.88 & 27.78 & 36.33 & Liat \\
\hline
\end{tabular}


Pada lapisan tanah 40-60 $\mathrm{cm}$ terlihat berbeda dari lapisan diatasnya, yaitu lebih halus dan termasuk kelas liat. Hal ini mungkin disebabkan karena proses pencucian oleh curah hujan yang tinggi di daerah peneltian. Seperti yang disampaikan Hakim et al. (1986) bahwa partikel-partikel liat bersama air perkolasi bergerak dari lapisan atas dan ditumpukkan di lapisan bawah sehinga kandungan liat lapisan bawah menjadi lebih tinggi dari lapisan di atasnya.

\section{Bahan Organik Tanah}

Pada semua lokasi pengambilan sampel, kandungan BO tanah (Tabel 3) menurun dengan kedalaman. Tingginya kandungan BO tanah permukaan dibanding ;lapisan di bawahnya disebabkan oleh sumber BO tanah utama berasal dari atas tanah. Diantaranya sumber BO diatas permuaan tanah yaitu sisa tanaman seperti daun, ranting dari pohon ataupun tanaman yang mati karena siklus hidupnya yang pendek seperti rumput dan tanaman permukaan tanah lainnya. Di samping itu, bangkai binatang yang mati di atas tanah juga berkontribusi terhadap BO tanah. Akan tetapi, didalam tanah atau di bawah permukaan tanah yang menjadi sumber BO adalah akar dan juga binatang tanah yang mati, yang jumlahnya sedikit dibanding yang diatas tanah.

Sesuai dengan yang didapatkan Yulnafatmawita (2004) pada Ultisol Limau Manis dan , Yulnafatmawita et al (2007) pada daerah hutan hujan tropik PinangPinang bahwa perbedaan penggunaan lahan mengakibatkan perbedaan kandungan $\mathrm{BO}$ tanah. Kemudian, BO tanah di lapisan bawah bisa juga berasal dari pencucian BO dari tanah lapisan diatasny, tetapi tidakbanyak terjadi.

Bila dilihat dari ke dua lokasi yang diteliti, kandungan BO tanah pada pertanaman manggis di daerah Koto Baru Kecamatan Payakumbuh pada umumnya lebih tinggi dari BO di Kecamatan Guguk. Hal ini mungkin dipengaruhi oleh vegetasi yang tumbuh pada lokasi penyampelan. Di samping pohon manggis, vegetasi lain misalnya tanaman yang diusahakan selain manggis ataupun rumput-rumputan yang tumbuh diatasnya. Kalau dilihat di lapangan, pada lokasi Koto Baru 1 (Kec. Payakumbuh), sumber BO tanah berasal dari bagian tanaman manggis yang mati dan juga dari tanaman semusim yang diusahakan penduduk disekitar pohon manggis. Dengan kata lain, pohon manggis berada pada perladangan tanaman semusim. Jadi sumber BO menjadi lebih banyak. Sedangkan di Kec Guguk, hanya lokasi Guguk 3 yang mempunyai kandungan $\mathrm{BO}$ yang lebih tinggi (termasuk kriteria sedang. Hal ini juga disebabkan karena tanaman manggis yang disample tanahnya berada dalam daerah yangdibiarkan ditumbuhi tanaman rendah atau tanaman permukaan seperti rumputrumputan, keladi, pakis, dan sebagainya. Tanaman yang demikian mempunyai siklus hidup yang pendek dan cepat menyumbangkan $\mathrm{BO}$ ke dalam tanah. Sesuai dengan hasil penelitian Yulnafatmawita et al (2007) bahwa penggunaan lahan kebun campuran dengan tanaman penutup tanah alami di daerah hutan hujan tropik Pinang-Pinang mempunyai kandungan $\mathrm{BO}$ tanah yang lebih tinggi dibanding kandungan $\mathrm{BO}$ tanah di bawah hutan.

Sampel tanah pada Guguk 1 dan Guguk 2 berasal dari pertanaman manggis yang berada pada pekarangan penduduk, tepatnya pada halaman belakang rumah. Lokasi pertanaman bersih dari rumput dan tanaman penutup tanah lainnya. Oleh sebab itu, sumber BO tanah hanya berasal dari tanaman manggis saja. Seperti yang disampaikan Ahmad (1980) bahwa vegetasi yang tumbuh pada suatu tanah akan mempengaruhi kandungan BO nya. Sumber BO tanah dapat berupa jaringan tumbuhan seperti daun, ranting, dan akar, serta dari semak, rumput, dan tanaman rendah lainnya (Soegiman, 1980).

Bahan organik tanah sanagt penting bagi kesuburan fisik, kimia, dan biologi suatu tanah. Hal ini disebabkan karena BO berhubungan erat dengan kegemburan tanah, retensi dan transmissi air, kemudian juga sebagai sumber hara bagi tanaman jika melapuk, dan sumber energi mikroba tanah dalam aktifitasnya merombak BO 
Tabel 3. Kandungan Bahan Organik, Bobot Volume, Total Ruang Pori, dan Permeabilitas Tanah pada Pertanaman Manggis di Kecamatan Guguk dan Payakumbuh Kabupaten Lima Puluh Kota

\begin{tabular}{|c|c|c|c|c|c|c|c|c|c|}
\hline Lokasi & $\begin{array}{l}\text { Kedalaman } \\
\quad(\mathrm{cm})\end{array}$ & $\begin{array}{l}\mathrm{BO} \\
(\%)\end{array}$ & Kriteria & $\begin{array}{c}\mathrm{BV} \\
\left(\mathrm{gcm}^{-3}\right)\end{array}$ & Kriteria & $\begin{array}{l}\mathrm{TRP} \\
(\%)\end{array}$ & Kriteria & $\begin{array}{l}\text { Permeabilitas } \\
\left(\mathrm{cm} \mathrm{jam}^{-1}\right)\end{array}$ & Kriteria \\
\hline \multirow{3}{*}{$\begin{array}{c}\text { Koto Baru Kec. } \\
\text { Payakumbuh } 1\end{array}$} & $0-20$ & 8.46 & Sedang & 0.76 & Sedang & 87.84 & Tinggi & 12.96 & Cepat \\
\hline & $20-40$ & 4.89 & Sedang & 0.92 & Sedang & 76.71 & Tinggi & 0.44 & Lambat \\
\hline & $40-60$ & 4.52 & Sedang & & & & & & \\
\hline \multirow{3}{*}{$\begin{array}{l}\text { Koto Baru Kec. } \\
\text { Payakumbuh } 2\end{array}$} & $0-20$ & 5.70 & Sedang & 0.75 & Sedang & 78.41 & Tinggi & 21.05 & Cepat \\
\hline & $20-40$ & 2.27 & Rendah & 1.43 & Tinggi & 66.34 & Sedang & 1.32 & Agak Lambat \\
\hline & $40-60$ & 1.99 & Sangat Rendah & & & & & & \\
\hline \multirow{3}{*}{$\begin{array}{c}\text { Koto Baru Kec. } \\
\text { Payakumbuh } 3\end{array}$} & $0-20$ & 4.69 & Sedang & 0.90 & Sedang & 76.14 & Tinggi & 4.06 & Sedang \\
\hline & $20-40$ & 3.21 & Rendah & 1.15 & Tinggi & 62.55 & Sedang & 0.12 & Lambat \\
\hline & $40-60$ & 3.13 & Rendah & & & & & & \\
\hline \multirow[t]{3}{*}{ Kec. Guguk 1} & $0-20$ & 3.75 & Rendah & 0.80 & Sedang & 69.80 & Sedang & 18.47 & Cepat \\
\hline & $20-40$ & 3.36 & Rendah & 1.01 & Sedang & 66.48 & Sedang & 0.39 & Lambat \\
\hline & $40-60$ & 2.47 & Rendah & & & & & & \\
\hline \multirow[t]{3}{*}{ Kec. Guguk 2} & $0-20$ & 3.19 & Rendah & 0.76 & Sedang & 77.12 & Tinggi & 4.93 & Sedang \\
\hline & $20-40$ & 3.09 & Rendah & 1.02 & Sedang & 70.52 & Sedang & 0.13 & Lambat \\
\hline & $40-60$ & 2.56 & Rendah & & & & & & \\
\hline \multirow[t]{3}{*}{ Kec. Guguk 3} & $0-20$ & 4.92 & Sedang & 0.86 & Sedang & 79.73 & Tinggi & 4.54 & Sedang \\
\hline & $20-40$ & 2.57 & Rendah & 1.41 & Tinggi & 74.04 & Sedang & 3.60 & Sedang \\
\hline & $40-60$ & 2.45 & Rendah & & & & & & \\
\hline
\end{tabular}




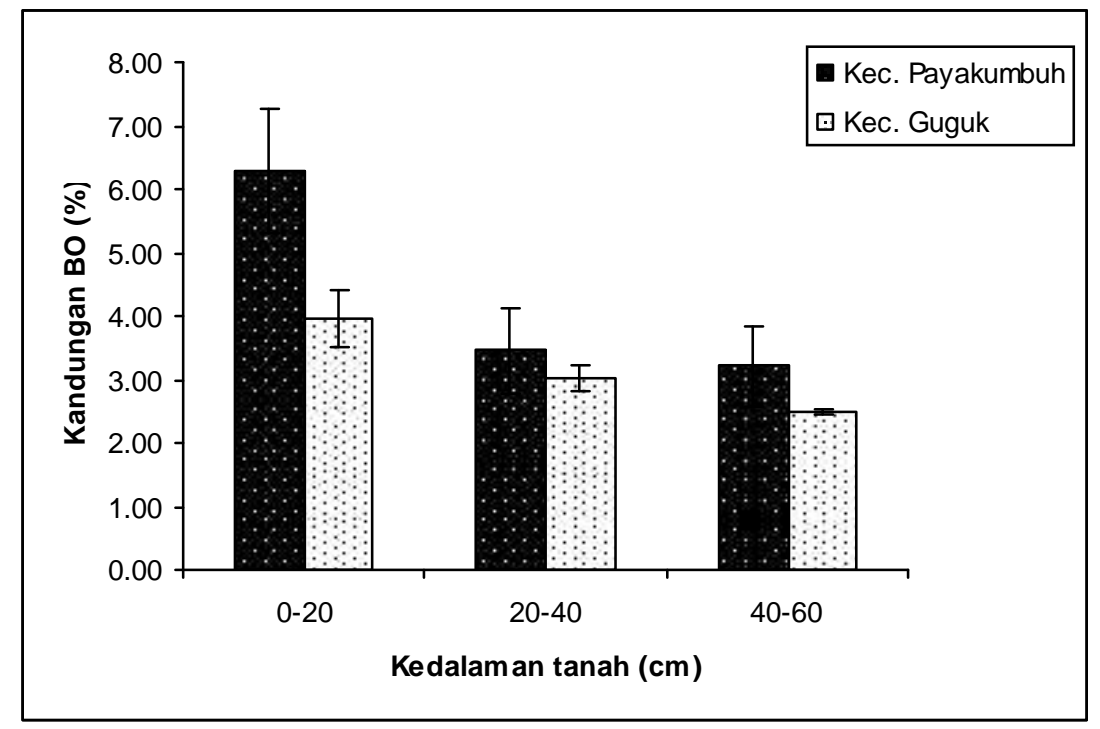

Gambar 2. Kandugan BO tanah pada pertanaman manggis di Kabupaten Lima Puluh Kota

menjadi hara tanaman. Oleh sebab itu, mempertahankan kandungan BO tanah pada suatu level tertentu merupakan suatu keharusan.

\section{Nilai Bobot Volume dan Total Ruang} Pori Tanah

Nilai bobot volume (BV) dan total ruang pori (TRP) suatu tanah saling berhubungan satu sama lain dan nilainya berbanding terbalik. Nilai TRP tanah akan naik jika BV menurun, demikian juga sebaliknya. Kedua nilai ini menentukan tingkat kepadatan atau prosentase ruang dalam suatu volume tanah. Baik nilai BV maupun nilai TRP dipengaruhi oleh tekstur tanah dan susunan partikelnya atau aggregat tanah, serta kandungan BO tanahnya. Semakin kasar tekstur tanah maka

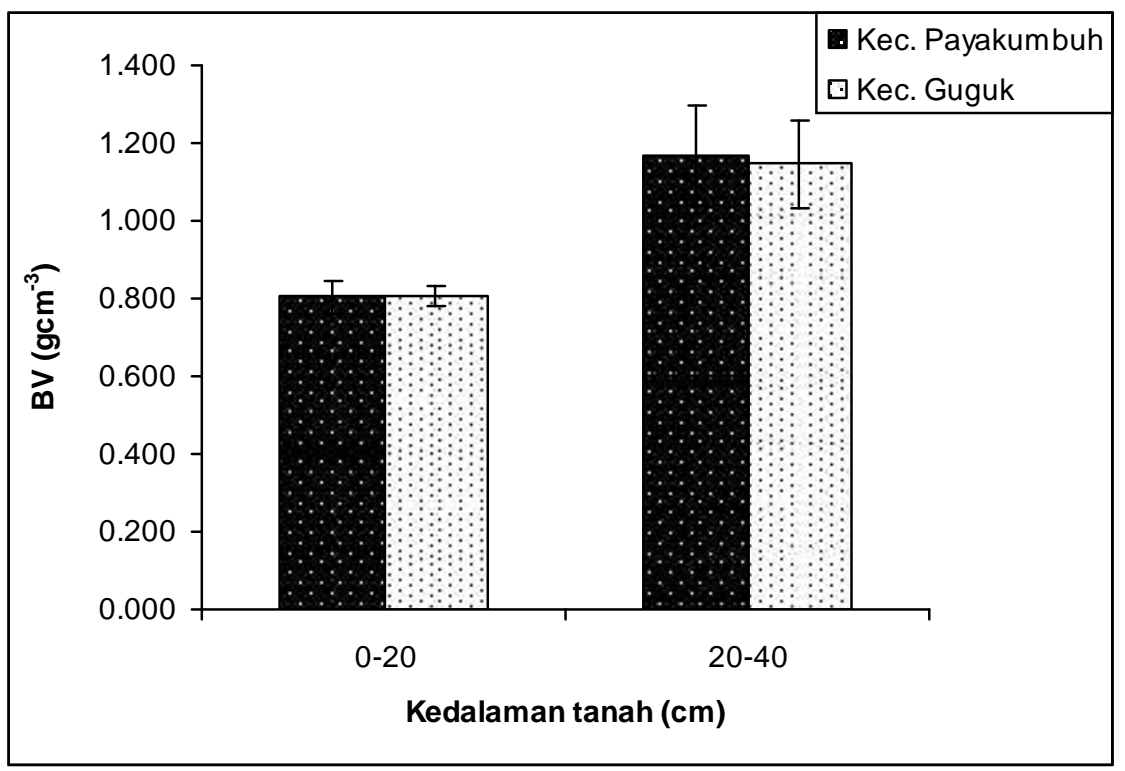

Cambar 3. Nilai BV tanah pada pertanaman manggis di Kabupaten Lima Puluh Kota 


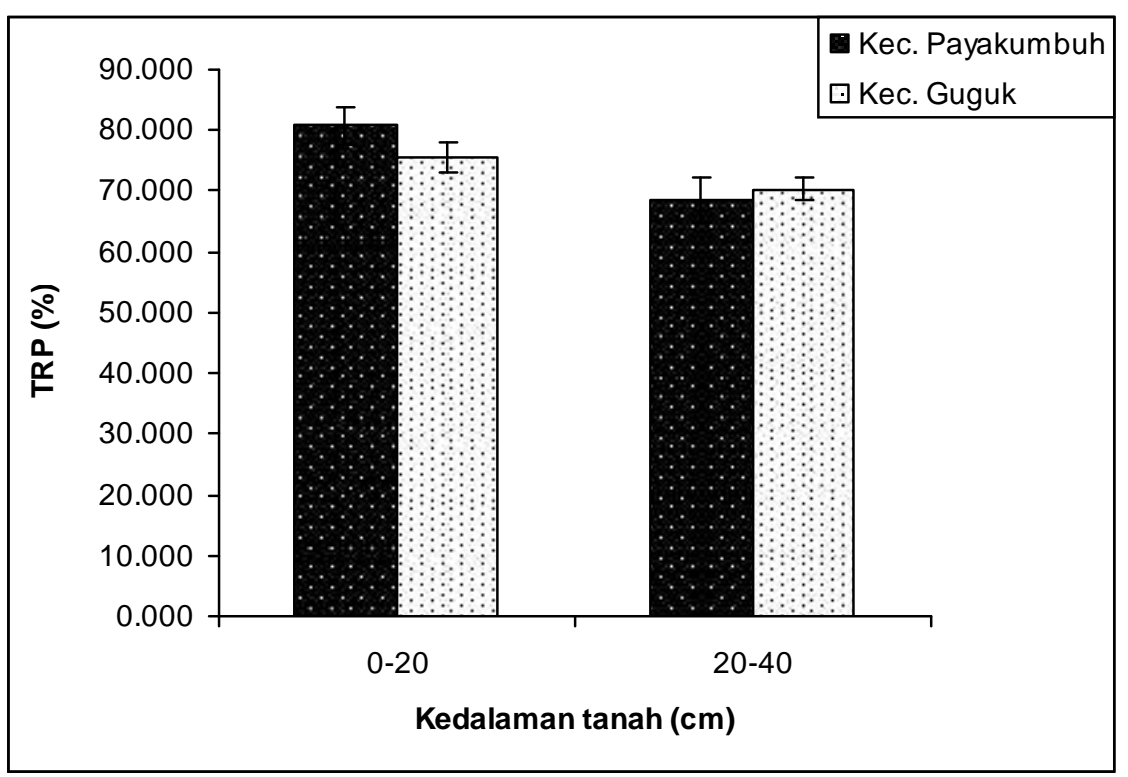

Gambar 4. Nilai TRP tanah pada pertanaman manggis di Kabupaten Lima Puluh Kota

nilai BV semakin tinggi dan TRP semakin rendah. Pada kondisi tekstur yang sama, tanah dengan kandungan $\mathrm{BO}$ yang tinggi akan mempunyai BV yang lebih rendah dan TRP yang lebih tinggi. Hal ini disebabkan oleh bobot BO itu sendir yang lebih ringan dari bobot mineral tanah.

Pada Tabel 2 diatas terlihat bahwa nilai BV tanah lapisan atas $(0-20 \mathrm{~cm})$ lebih rendah dari nilai $\mathrm{BV}$ lapisan di bawahnya.
Hal ini disebabkan oleh karena perbedaan kandungan BO tanah, walapun tekstur tanahnya sama. Demikian juga dengan nilai TRP tanah yang menurun dengan penurunan kandungan BO tanah. Karena BO berperan merajut butir tanah membentuk aggregat dan menciptakan ruang diantara aggregat tersebut. Yulnafatmawita (2004) dan Yulnafatmawita et al (2007) mendapatkan hal yang sama.

\section{Nilai Permeabilitas Tanah}

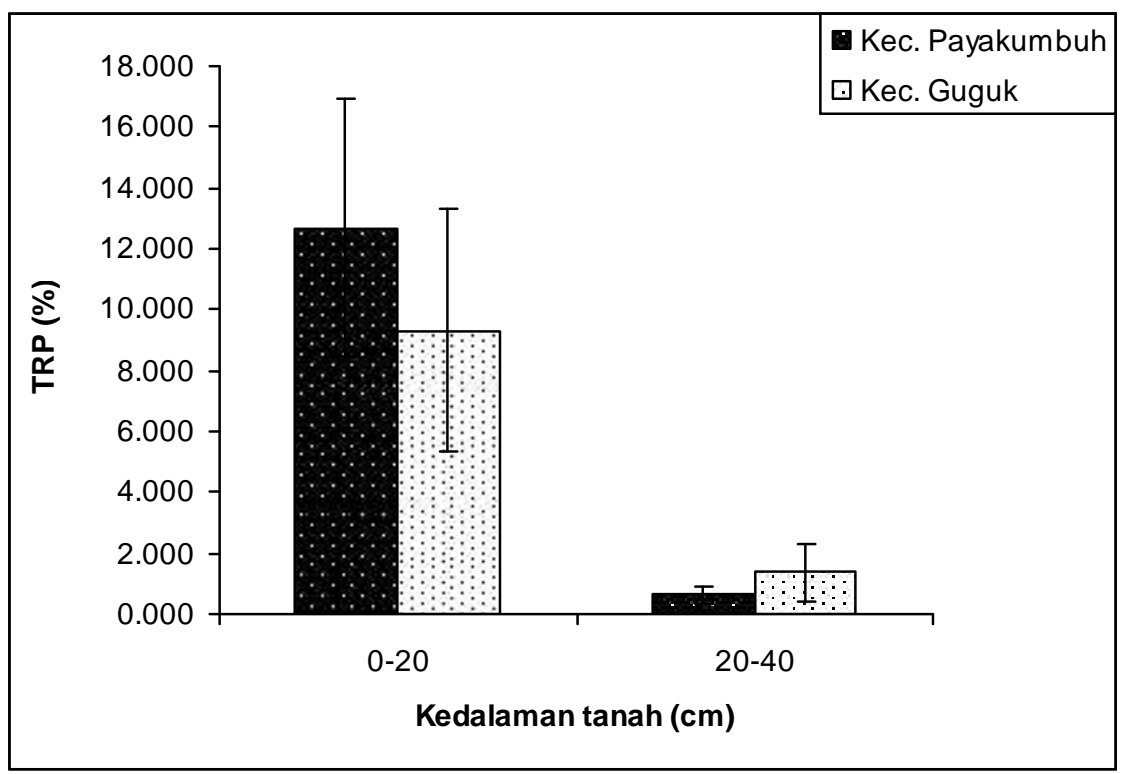

Gambar 5. Nilai permeabilitas tanah pada pertanaman manggis di Kabupaten Lima Puluh Kota 
Nilai permeabilitas tanah terhadap air atau kemampuan tanah untuk meloloskan air pada kondisi jenuh jauh lebih tinggi pada lapisan 0-20 $\mathrm{cm}$ dibanding lapisan di bawahnya. Hal ini dipengaruhi oleh berbagai faktor, diantaranya tekstur, struktur atau sistem aggregasi tanah, serta kandungan BO tanahnya. Selama tekstur tanah pada kedalaman 0-20 dan 20-40 cm mempunyai kelas yang sama menurut segitiga tekstur USDA, maka nilai permeabilitasnya dipengaruhi oleh faktor yang lainnya. Sistem aggregasi tanah dalam penelitian ini tidak diamati, tetapi mungkin saja berbeda akibat perbedaan kandungan $\mathrm{BO}$ tanah pada masing-masing lapisan. Kandungan BO yang tinggi pada tanah di lapisan atas menyebabkan proses aggregasi tanah yang baik, karena BO mampu menyatukan butir tunggal menjadi aggregat mikro dan aggregat mikro menjadi aggegat makro yang mempunyai ruang pori seimbang atara pori berukuran kecil dan besar. Kondisi yang demikian menyebabkan tanah mampu melewatkan air lebih cepat persatuan waktunya dibanding tanah yang sama tetapi dengan kandngan BO yang lebih rendah.

Selain berperan merajut butir tunggal menjadi aggregat, $\mathrm{BO}$ juga mampu memantapkan aggregat yang terbentuk sehingga lebih tahan terhadap energi input yang diterima oleh tanah itu sendiri. Aggregat tidak mudah pecah kena energi kinetik pukulan butir hujan, atau akibat injakan kaki binatang, ataupun alat/mesin mesin pertanian. Oleh sebab itu, tanah dengan aggregat yang mantap dapat meloloskan air secara kontinu dengan lau yang sama.

Berdasarkan Tabel 3, dapat disimpulkan bahwa kandungan BO tanah yang tinggi pada lapisan permukaan (0-20 $\mathrm{cm})$ menyebabkan permeabilitas tanah juga tinggi. Hal ini disebabkan karena BO dapat menciptakan aggregat yang mantap dengan tipe struktur yang remah, yaitu yang mempunyai keseimbangan pori antara pori makro dan pori mikro.

\section{KESIMPULAN DAN SARAN}

Berdasarkan hasil analisis di laboratorium terhadap sifat fisika tanah pada pertanaman manggis di Kabupaten Lima Puluh Kota, maka dapat disimpulkan bahwa:

1. Tekstur tanah pada kedua daerah penelitian, kecamatan Payakumbuh dan Kec. Guguk, termasuk agak kasar, yaitu lempung berdebu pada lapisan atas (0$40 \mathrm{~cm}$ ) dan liat pada lapisan bawah (40$60 \mathrm{~cm}$ ).

2. Kandungan BO tanah termasuk kriteria rendah-sedang, di kecamatan Payakumbuh kandungan BO tanah cendrung lebih tinggi dari kecamatan Guguk

3. nilai $\mathrm{BV}$ tanah termasuk sedang di lapisan atas $(0-20 \mathrm{~cm})$ dan sedang-tinggi di lapisan dibawahnya $(40-60 \mathrm{~cm})$.

4. Nilai TRP tanah berkisar dari tinggi di lapisan atas dan sedang di lapisan bawah

5. Nilai permeabilitas tanah pada lapisan permukaan termasuk cepat, sedankan lapisan dibawahnya termasuk agak lambat - lambat

\section{DAFTAR PUSTAKA}

Fiantis, D. 2001. Pengembangan Sistem Informasi Geografi Tanah Vulkanis Sumatera Barat untuk Peningkatan Produksi Tanaman Hortikultura. Proposal Riset Unggulan Terpadu IX. Universitas Andalas. Padang. 13 Hal.

Yuniarti, Yulnafatmawita, dan Sudewi Isminingsih. 2007. Evaluasi Kesesuaian Lahan Dan Potensi Produksi Tanaman Manggis (Garcinia mangostana L.) di Kab.50 Kota. J. Solum Vol. IV No.2

Gee, G. W. and Bauder, J. W. 1986. Particle-size analysis. In "M ethods of Soil Analysis" Part 1 Physical and mineralogical Methods, edited by A.Klute, ASA-SSSA Publ., Madison, 383-412 page

Brady, N.C. 1984. The Nature and Properties of Soils. Ninth Edition. Macmillan Publishing Company. New York. 750 pages 
Foss, J.E., Moormann, F.R., and Rieger, S. 1983. Inceptisols. In Pedogenesis and Soil Taxonomy. II. The Soil Orders. Edited by L.P.Wilding, N.E.Smeck, and G.F.Hall. Elsevier Amsterdam. 355-381 page.

Hakim, N., Nyakpa, M.Y., Lubis, A.M., Nugroho, S.G., Soul, M.R., Hong, G.B., and Bailey, H.H. 1986. DasarDasar Ilmu Tanah. Universitas Lampung Bandar Lampung. 762 halaman.

Yulnafatmawita. 2005. Hubungan antara kandungan bahan organic dan stabilitas aggregate tanah akibat perubahan penggunaan lahan. Prosiding Seminar Tahunan BKS-PTN 25-27 April 2005 di Universitas Jambi.

Yulnafatmawita, Luki, U., dan Yana, A. 2006. Kajian Sifat Fisika Tanah Beberapa Penggunaan Lahan di Bukit Gajabuih Kawasan Hutan Hujan Tropik Gunung Gadut Padang. Prosiding Seminar BKS-PTN Barat
23-26 Juli 2007 di Pekan Baru hal 122-128.

Yulnafatmawita, Hermansah, dan Saidi, A. 2007b. Dinamika Bahan Organik Tanah Bukik Pinang-Pinang Kawasan Hutan Hujan Tropis Super Basah Sumatra Barat. Laporan Penelitian Fundamental DP2M DIKTI 2007.

Ahmad, F. 1980. Dasar-Dasar Ilmu Tanah. Fakultas Pertanian Universitas Andalas Padang.

Soegiman. 1982. Ilmu tanah. Terjemahan Buckman and Brady "The Nature and Properties of Soil" Bhratara Karya Aksara. Jakarta.

Tan, K. H. 2001. Environtmental Soil Science. Marcel Dekker, Inc. New York.

Tan, K. H. 1998. Principles of Soil Chemistry. Third Edition Resived and Expanded Marcel Dekker, Inc. New York.

521 pp. 